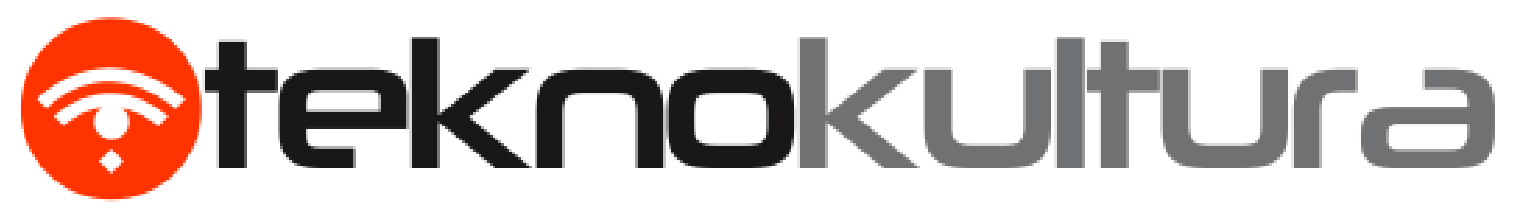

\#LyLES, D. et al. (2016). Generative Contexts: Generating value between community and educational settings, Revista Teknokultura Vol. 13(2), 613-637.

Recibido:

Aceptado con modificaciones:

Aceptado finalmente:
08-06-2016 Open peer review

23-08-2016 http://revistas.ucm.es/index.php/TEKN/pages/view/opr-52845

17-11-2016

\title{
Generative Contexts: Generating value between community and educational settings
}

\author{
Contextos Generativos: Generando valor \\ entre la comunidad $y$ los espacios educativos
}

\author{
Dan Lyles, Michael Lachney, Ellen K. Foster \& Zoe Zatz \\ Rensselaer Polytechnic Institute \\ danlyles@gmail.com - michael.lachney@gmail.com - \\ el.fostek@gmail.com - zatzz@rpi.edu
}

\begin{abstract}
As educators and researchers, the authors of this paper participated, at different points in time, in a National Science Foundation funded research program to place culturally responsive education into generative justice frameworks. We discovered that the mechanisms to create generative contexts - contexts where value can possibly be returned to the community where the people generating that value live and work-in-school, after-school, and not-school were not uniform and required individual attention and care. One can think of generative contexts as the educational preconditions for generative justice. We aim to show how generative contexts are crucial to understanding a larger theory of generative justice. To do this we
\end{abstract}


provide three examples of generative contexts. First is a generative context in-school, where a technology teacher brought a community hairstylist into her classroom to help teach computer programming through cornrow braiding; a skill relevant to her African American students. Next is a generative context after-school where a student demonstrates soldering skills that she learned from family members. The third is a not-school "E-Waste to Makerspace" workshop where students created garden-technology designs for low-income communities.

\section{KeYWORDS}

Asset building; culturally responsible teaching; educational programs.

\section{Resumen}

Como educadores e investigadores, los autores de este artículo participaron en un programa de investigación financiado por la NSF (Fundación Nacional para la Ciencia de Estados Unidos) con la intención de situar la educación sensible a la diversidad cultural en el marco de la justicia generativa. Descubrimos que los mecanismos para crear contextos generativos-contextos en los que existe la posibilidad de retornar valor a la comunidad donde se genera, vive y trabaja-escolares, extraescolares y no-escolares no eran uniformes y, por tanto, requerían una atención y cuidado individuales. Podemos entender los contextos generativos como los requisitos para la educación en materia de justicia generativa. Nuestro objetivo es mostrar la crucial importancia del contexto a la hora de comprender la teoría de justicia generativa en su sentido más amplio. Para ello proporcionamos tres ejemplos de contextos generativos. El primero, un contexto escolar generativo, donde una profesora de tecnología invitó a clase a una comunidad de peluqueros para ayudar a enseñar a los alumnos geometría transformacional haciendo trenzas; una destreza, además, relevante para sus estudiantes afro-americano/as. El segundo es un contexto extraescolar, en el que un estudiante demostró sus habilidades como soldador, las cuales había aprendido de miembros de su familia. El tercero es un taller no escolar, "E-waste to makerspace", donde los estudiantes diseñaron un jardín tecnológico para personas con bajos recursos.

\section{Palabras Clave}

Construcción de activos; educación culturalmente responsable; programas educativos. 


\section{Contents}

1. Introduction

2. Generative context case 1: in-school

3. Generative context case 2: after-school

4. Generative context case 3: not-school

5. From context to justice

6. Conclusion

7. References

\section{Contenidos}

1. Introducción

2. Caso contexto generativo 1: escolares

3. Caso contexto generativo 2: extraescolares

4. Caso contexto generativo 3: no-escolares

5. De contexto a justicia

6. Conclusión

7. Referencias 


\section{Acknowledgment}

We would like to thank Ron Eglash and the three anonymous reviewers for their feedback on this paper. We would also like to give a special thanks to Mara Dicenta Vilker and Hined Rafeh for helping with translation.

This work was supported by the National Science Foundation [grant number DGE-0947980]. 


\section{Introduction}

In 2015, the Obama administration acknowledged that students in the United States are spending too much time on tests and recommended that testing take up no more than two percent of the school year (Zernike, 2015). This announcement came after years of protests amongst parents, children, and teachers against what Jesse Hagopian (2014) has identified as "testocracy": prioritizing state tests above all else. The fact that the US has remained average in science and math compared to other national education systems (Drew, 2011) helped to foster the national anxiety that fueled testocracy. While students may know that doing well on their state test has an effect on school funding and their teachers' evaluations, this knowledge remains abstract at best, and provides little in terms of family or community use-value. This has proven especially problematic for communities of color who must endure culturally irrelevant school curricula and structure.

As of April 2016, white students in the Los Angeles Unified School District are one grade level ahead while their African-American colleagues are two grade levels behind (Rich et al., 2016). In New York City, the grade level gap is 2.3 grade levels (Rich et al., 2016). There are many reasons for why students of color are being left behind by American politicians, not least of which have to do with a lack of economic access, failing public infrastructure and the deindustrialization of urban centers (Anyon, 2014; Lipman, 2010). This abstraction of education from students' everyday lives is an alienating condition, opposed to the vision of liberatory education posited by educator and philosopher Paulo Freire (1970): "Education as a practice of freedom - as opposed to education as a practice of domination-denies that man is abstract, isolated, and independent, and unattached to the world; it also denies that the world exists as a reality apart from people" (p. 81). In other words, the material conditions of students' lives must be connected to the social goals of schooling. Given the recent push to scale back testocracy, what alternatives can the administrations look to for cultivating unalienating conditions for education?

One pathway toward unalienated education is culturally responsive teaching (CRT). Since the early 1990s, CRT research and practices have helped to build community assets that are based on the cultural experiences and heritages of underrepresented students. The goal is to transform curriculum and school structure to be more inclusive of marginalized knowledge systems and material practices (Lipka et al. 1998). When Gloria Ladson-Billings (1995) began to popularize CRT, she meant it to signal the simultaneous development of students' academic 
success, cultural competence, and socio-political consciousness. Geneva Gay (2010) has gone on to characterize the organizational reach of CRT. She describes it as an "equal educational opportunity initiative" that is based on accepting and building upon ethnic differences to empower students of color in personal and social development. Ladson-Billings and Gay both argue against the "deficit" model of education that views students' lives outside of school as barriers to be overcome. Instead, CRT affirms students' families, backgrounds, and communities as cultural and educational assets to be included in learning content and lesson structures (Ladson-Billings, 1995; Gay, 2010; Brown-Jeffy \& Cooper, 2011). The strength of CRT is its ability to overlap school and not-school content in single lessons. This has allowed CRT to be used in-school where teachers meet district or state curriculum requirements; afterschool where in-school content can be extended and/or supplemented by enrichment activities; and not-school where learning is based on community goals and students' interests. Yet, the actual activity design and implementation of CRT have ranged from culturally shallow to deep. In its most trivial form, characters' names and skin colors change in word problems, while deeply engaged forms are developed through design activities that include community input (Lachney 2016).

Because CRT can be reinterpreted in shallow or trivial forms, it is helpful to have some guide by which we can distinguish its deeper variants. To do this we will use the framework of "generative justice," defined by Ron Eglash (2016) as the rights of a community to nurture self-sustaining paths for circulating value that the community itself generates. Over the course of six years, as part of National Science Foundation funded educational research, we used generative justice as a framework to develop CRT lesson structure and content in collaboration with teachers, university-technologists, and community members. In the context of education, we sought to find ways for schools and communities to build cultural and educational assets to their mutual benefits. We use the term "assets" to refer to the social, cultural, and technological formations that constitute a student's "personhood, communities, background, and families" (Scott et al., 2015, p. 3). These assets may be identified as part of students' heritage, community, family, or popular culture. As an example, Bennett et al. (2016) explore instances where value was generated when Adinkra artisans in the West African nation of Ghana helped researchers from the US and teachers from Ghana created a computing activity that overcame the problem of low student-to-computer ratios in a local school. Unlike standardized testing that extracts value from communities and students, these artisans were able to design miniature Adinkra stamps as an educational asset to schools, while schools were able to help preserve traditional stamping practices important to the 
Adinkra-artisan community (Lachney et al., 2016). Building on Dan Lyles' (2016) framework for extending generative justice into community settings, we define the kind of system that focuses on building community assets as a "generative context." In the case above, teachers and artisans created a generative context where value was intentionally circulated to build Adinkra as an asset for both school and community benefit.

Generative contexts can be (somewhat tautologically) identified as environments and interactions where generative justice is more likely to occur. Identifying a system's generative potential is more of an art than a science, and often trial and error is required as we experiment with various potentials. Sometimes an older generation sees a practice as significant in ways that youth do not; similar mismatch can occur by gender and other identities. When successful, the pieces taken together create circumstances where the generative potential of a system is likely to materialize. The three examples of CRT below are narratives taken from a National Science Foundation research project and detail the ways in which the contexts for generative justice may be possible. In the tradition of John Dewey's (1915) progressive educational experimentation, we explore generative justice as a practical framework for developing deep CRT activities through blending research with classroom practice. While we certainly hope for educators to incorporate this CRT research into their practices for the ends of generative justice, when considering if these experiments can be reproduced in other contexts we aim to be both empirical and speculative. On the one hand, they detail specific cases where community knowledge is used as part of an educational experience for in-school, after-school, and not-school. On the other hand, many of these examples are in nascent form; only an initial set of culturally situated experiments on how value might circulate between schools and communities.

\section{Generative context case 1: in-school}

The first case study we explore focuses on cultivating the context for generative justice "inschool." In the US, in-school is often synonymous with rigid schedules, standardized content, and state testing. What kind of generative context can be cultivated when confronted with these constraints? To put this question another way, how might community assets be built to the benefit of students and their communities as part of in-school curriculum? When we place CRT in a generative justice context to be cultivated in-school, value between schools and communities are generated when an asset has both educational value-it can be used to meet 
the demands of in-school-and cultural value - it strengthens the existing value already in the community.

To explore what it takes to create a generative context in-school, we detail the implementation of one culturally responsive educational technology, Cornrow Curves, which was used to teach computer programming in an Upstate New York middle school. While computer programming was not standardized in this class, many technology teachers make it part of their curriculum, acknowledging the increasing importance of coding and computational thinking in work and higher education. Cornrow Curves is designed to build braiding as an educational asset that has curricular relevance for technology teachers and as a cultural asset that has relevance for parents and other community members (Eglash et al., 2006). In its current version, Cornrow Curves aids in computer programming lessons through simulating cornrow hairstyles (Lachney, 2016).

The graphical user interface is similar to MIT's Scratch, in which students drag, drop, and snap together visual "blocks" of code that represent rules and functions. However, unlike the "content agnostic" design of Scratch, the Cornrow Curves software is "content-aware" (Lachney et al., 2016; Richard \& Kafai, 2016), meaning its development is based in building cultural assets that are also educational assets in the areas of science, technology, engineering, and mathematics (STEM). This focus on STEM is intentional. The prevalence of multiculturalism in humanities and the absence of multiculturalism in STEM education sends an implicit message that STEM fields are only for those of European descent (Eglash, 1997). Alternatively, Cornrow Curves is based on the work of mathematicians and technologists to uncover non-Western and specifically African origins of computational and mathematical thinking. This research suggests that cornrow designs can help students see braiding in relationship to mathematical knowledge that is an asset to African American communities (Eglash et al., 2006) and global African Heritage (Eglash, 1999).

To cultivate a generative context in an in-school technology classroom using Cornrow Curves, we brought in Angela ${ }^{1}$, an established African American hairdresser from the surrounding area to work with a technology teacher, introduce the software, and explain to students her entrepreneurial background. Angela understood the importance of including underrepresented students' assets in technology education, and was excited by the prospect that cornrow braids are computationally significant. Her presence in the classroom helped us

\footnotetext{
${ }^{1}$ Angela is a pseudonym used to protect the identity of our informant and collaborator.
} 
to create a generative context where we could build braiding as an educational asset while strengthening it as a legitimate topic from students' lives that could be discussed in the classroom. While math and programming can be taught using a wide array of software, Cornrow Curves actively supported a less alienated form of education by establishing computational thinking in students' lived experiences and community expertise.

During the first day of the lesson, Angela showed students how to braid cornrows. Students that already knew how to braid came up and showed their method. We then had students read through the cultural context page on the Cornrow Curves website, using worksheets as a reading guide. During this time, many students would get up and practice braiding on one of the mannequins that Angela brought into the classroom. The following day, students went through the Cornrow Curves tutorial to learn how to use the software. When students completed the tutorial, they moved on and used the full version of the software to create their own cornrow designs (see Figure 1).

FiguRE 1. A STUDENT'S DESIGNED BASED ON A CORNROW ALGORITHM

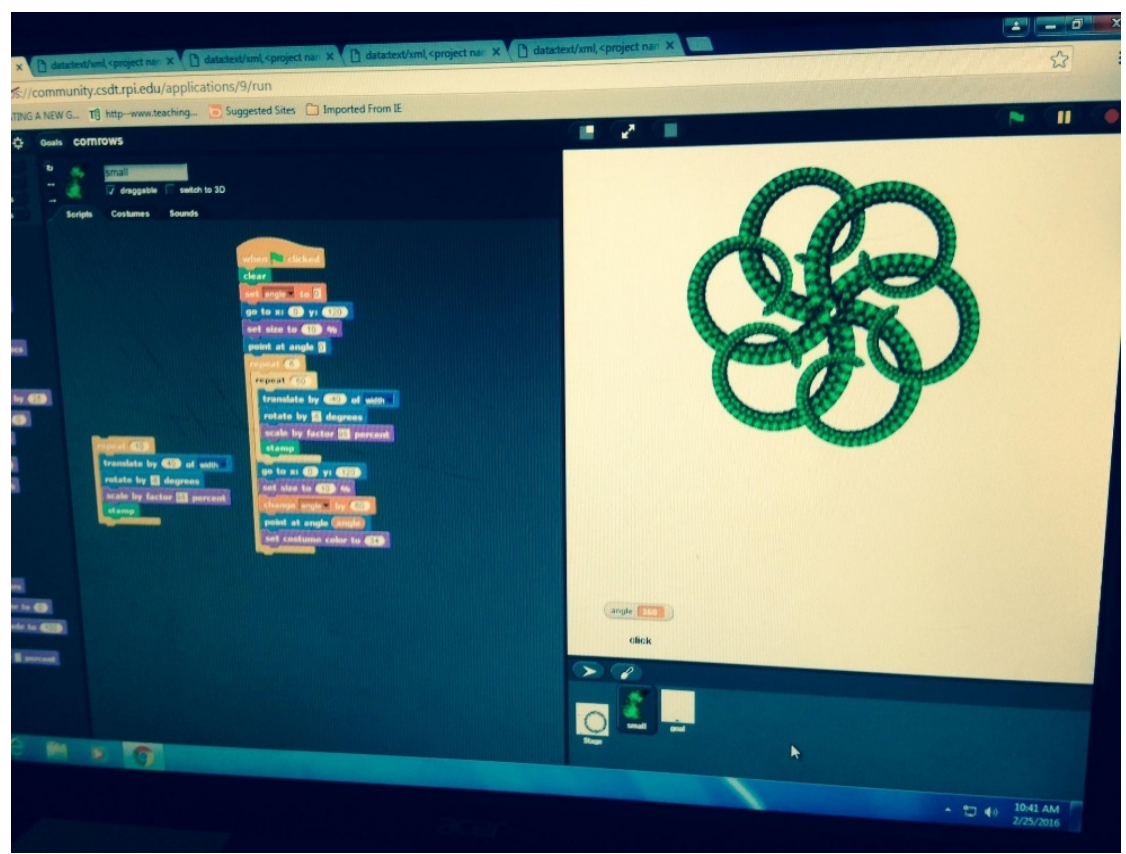

Source: Own production.

In addition to students and teachers being excited to have Angela in the classroom, staff and teachers from other areas of the school heard about what we were doing and showed up 
periodically to participate and lend their own expertise. While it might seem strange to position a hairstylist as an expert in a technology classroom, Angela is an example of an entrepreneur who came from a similar socio-economic background as many of the students in the school. In complete contradiction to the accepted wisdom that STEM superstars will best inspire students, their excitement supports research that suggests low-income students' testscores are impacted more when role models are also from low-income socio-economic status (Nguyen, 2008).

The festive atmosphere was enhanced by Angela's own enthusiasm, explaining to students how computing and math was rooted within her own practice (a subject she had only recently adopted in collaboration with our group), and how it could be learned through hair braiding simulations. Thus, we saw how the creation of a generative context allowed students to interchange community and school value. For example, during the middle of the Cornrow Curves lesson, one student excitedly exclaimed, "That's math!" while Angela was using transformational geometry terms to describe the braiding process. According to the technology teacher this particular student, in addition to several others, did not normally engage in class activities. That day these students excelled, making rainbow-colored cornrows (see Figure 2) and sharing their coded simulations with other students.

FiguRE 2. A STUDENT's' RAINBOW COLORED CORNROW DESIGN

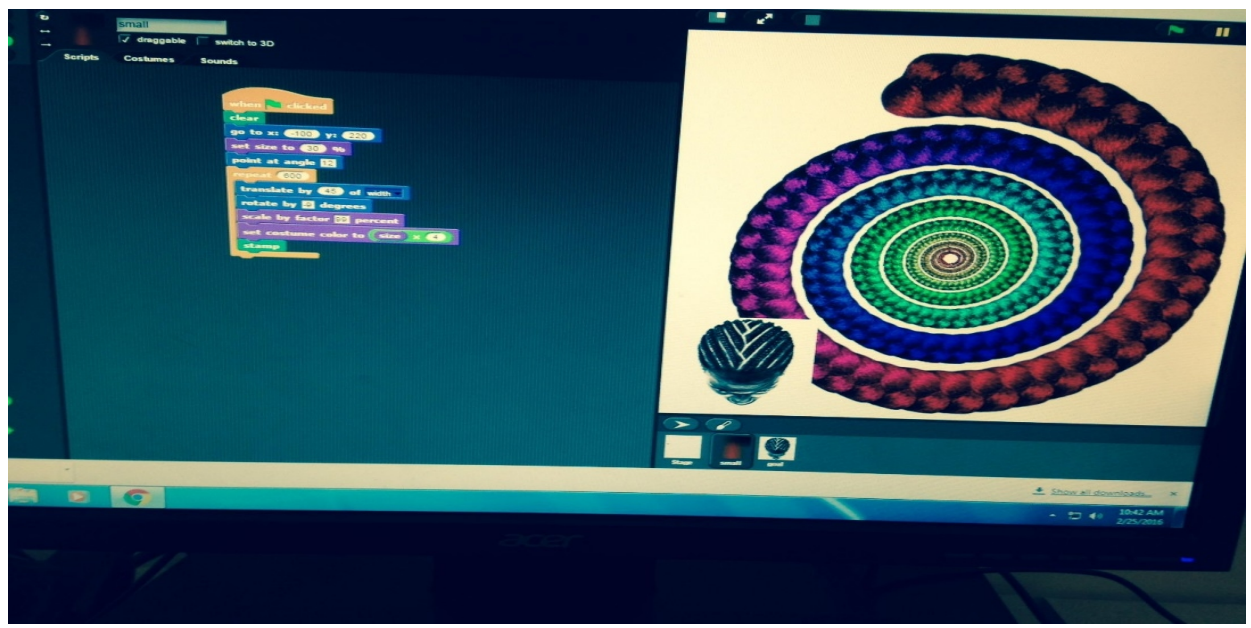

Source: Own production. 


\section{Generative context case 2: after-school}

Historically, the Do-It-Yourself (DIY) movement has focused on grassroots projects and the cultivation of lay expertise for the purpose of low-cost personal fabrication. The DIY movement started in opposition to the purchasing of consumer goods and personal empowerment through skill acquisition, often manifesting in the cultivation of hobbies such as home improvement, car modification (Chappell, 2001), ham radio fabrication (Haring, 2008), simple electronics kit assembly, woodworking, and the running of local music venues (Spencer, 2005). In the mid-2000s, an off-shoot of these DIY cultures began to further manifest in the form of the "Maker Movement," maker cultures, and makerspaces. Makerspaces are shared co-working spaces where individuals gather to exchange tools, skills, and a collective interest in project-based learning. Each maker group or space is very particular to the community out of which it develops and then further cultivates-no two are exactly alike in relation to the skills, tools, and community involved. Some scholars argue that the Maker Movement is just another consumerist trend geared towards the buying of things (such as tools, kits, and electronics) in order to make more things (Morozov, 2014). However, more radical groups within the Movement are interested in community development and engagement, particularly in the form of radical pedagogies and social entrepreneurship (Toupin, 2014). A truly diverse landscape, hacklabs (Maxigas, 2014) are an even more subversive version of shared-tool spaces that function outside of the Maker Movement but are aligned with the practices of sharing tools, skills, and space.

Pedagogically connected to Papert's (1993) “constructionism” and other learning-by-doing philosophies, maker programs in the United States, such as the Maker Education Initiative, the DARPA MENTOR program, and the Youth Makerspace Playbook (2015), have started to impact both public and private educational endeavors. Reflective of traditional programming such as Home Economics and Shop Class, Maker educational programming has great promise in after-school settings particularly. Yet it also holds the possible pitfall of reproducing cultural norms or cultural capital in terms of gender, race, and class differentiation. This includes the importance of some knowledge production practices over others. This section queries, how might it push through these tendencies toward generative justice for resource poor communities? What could prevent it from being generative justice? Why is it important to create a generative context in after-school settings? 
One failure to create a generative context for learning-by-doing practices includes the Defense Advanced Research Projects Agency (DARPA) Manufacturing Experimentation and Outreach (MENTOR) program (Dougherty, 2012), which started in 2012 as a four-year pilot. It focused on narrow-minded competitively-driven projects such as building go-carts that launch missile-like objects. By using pre-determined tasks and programming that did not allow for creative play or community-oriented projects, the DARPA MENTOR initiative failed to tap into and enable the enrichment possibilities for Maker programming. Its technocentric focus did not address important concerns such as pedagogy, community, or the context for how knowledge and technologies are shaped. However, there are also successes within the maker community in terms of community-driven educational projects, demonstrating a diversity of ideology within maker practices. One such success is the Philadelphia Maker Jawn, run out of Northeast Philadelphia regional public library branches. Rather than the technocentric focus of DARPA's MENTOR initiative, Maker Jawn is driven by an interest-based model that provides resources, materials, and sample projects for local community members. Teachers (known as mentors) in this program hope to cultivate community development. They let technological use and education grow out of community needs, aspirations, and pre-existing knowledges. In one branch, the lessons focus on cooking food and learning about local farms and urban gardening. Technology is used, but instead of competitively-driven projects, students cook and create instructional videos together. Thus, technology is incorporated in a more organic and generative manner that is based on student motivations in cooking and community goals around local food justice.

Inspired by more socially responsive maker programs, we explored how to implement a meaningful generative context via an after-school program. This program was connected to and created in collaboration with an inner-city middle school science classroom in Upstate New York. In it, we sought to develop trade and making skills that students could employ to their benefit outside of school. Unfortunately, much of the in-school science content was geared toward preparing students for testing, which made experimentation with maker cultures difficult for the teacher to teach and the students to learn. Over time it became clear that despite the teacher's best intentions the class had become one where he was required to teach to the test. This left little room for helping students explore their own communities and interests. 
FIGURE 3. THE DYNAMIC RESULTS OF PLAYING WITH DIFFERENT COLORED CIRCUITRY MATERIALS

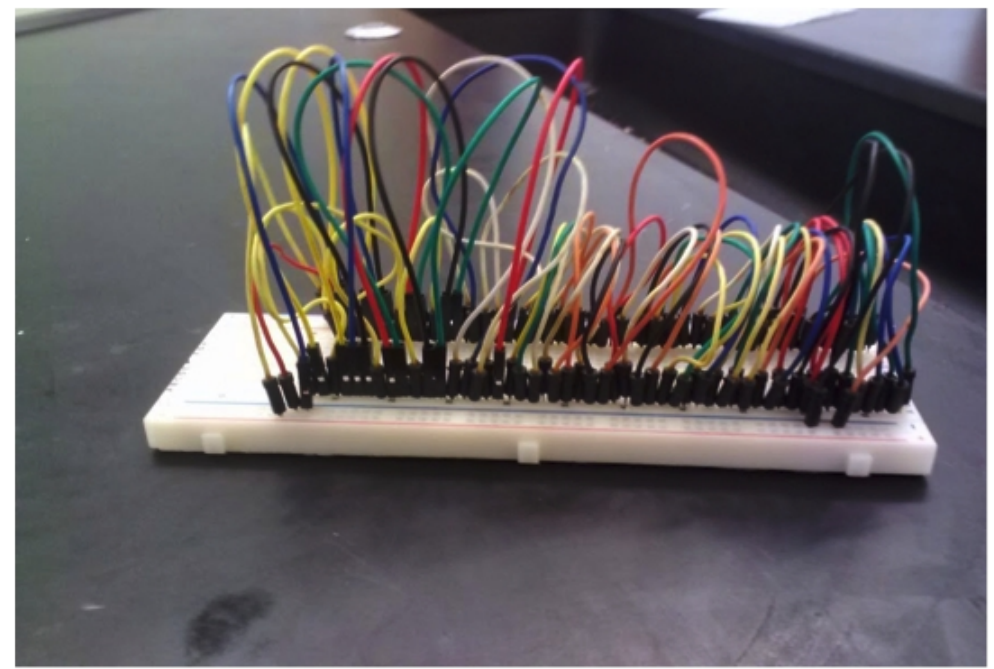

Source: Own production.

FIGURE 4. STUDENTS WORKING TOGETHER TO LEARN ABOUT THE INNER WORKINGS OF PRINTERS.

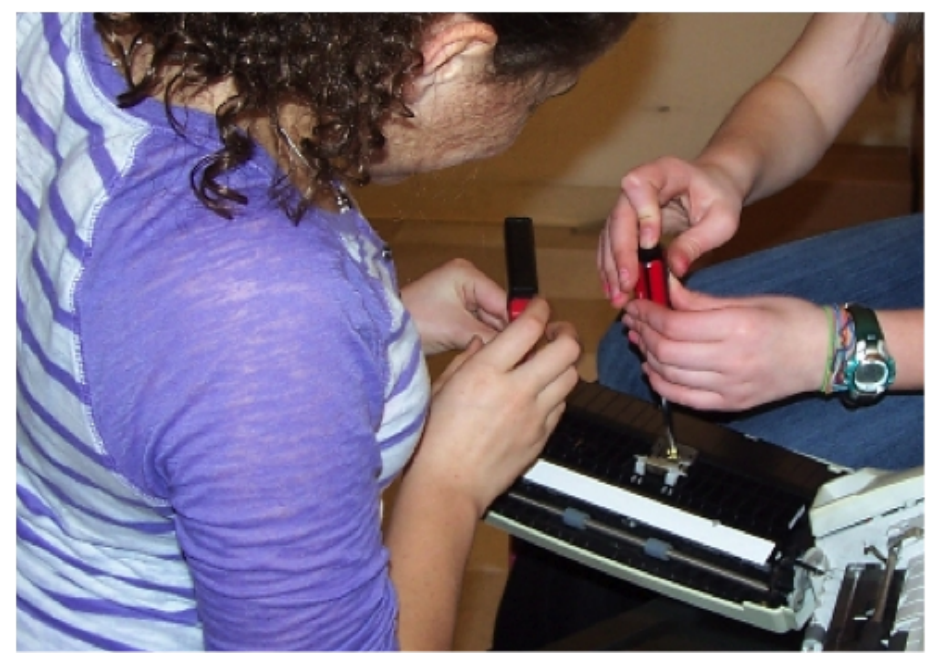

Source: Own production.

In an attempt to break away from the constraints of the content of in-school science, the program began to run after-school. Through project-based learning it a focused on simple 
circuitry, material fabrication, and awareness of the environmental problems of electronic waste (e-waste) associated with technological development. While the workshop had predetermined projects for students—often involving soldering, LEDs, environmental sensors, old printers and DVD drives - the program also allowed for considerable amounts of play (Figure 3 ), working to identify student interests, and fostering peer-to-peer learning dynamics (Figure 4). This often resulted in building moments of communal learning between adults and students. It also allowed for setting the groundwork, or generative context, through which students felt comfortable and were encouraged to bring their local community knowledge or experiences into after-school. The results were surprising and had unexpected outcomes.

While teaching a soldering workshop that involved simple circuitry and sound exploration using repurposed electronic materials, one student decided to focus on something different. She started to use the pieces and strands of solder as a building material, creating different shapes and animals out of the solder available. It was never expected that students would use the material in this way, but it was a welcome caveat to the project at hand and she was encouraged to use the solder in this artistic manner. When asked if she soldered, or had done this before, she referenced her uncle who is a welder and often makes sculptures. Seeing a similar set-up (albeit smaller), the student took to replicating and playing with the solder in a way that her background and community knowledge enabled. By encouraging more openended and playful projects, this workshop gave her an outlet to explore the materials in a potentially generative manner, and in a way that connected back to her not-school experiences. Thus, the learning moment was enriched by her situated cultural context, and gave weight to what Haraway (1991) calls "situated knowledges," an understanding of knowledge that the after-school program strove to cultivate:

Situated knowledges require that the object of knowledge be pictured as an actor and agent, not as a screen or a ground or a resource, never finally as slave to the master that closes off the dialectic in his unique agency and his authorship of "objective" knowledge

(Haraway, 1991, p. 592).

For example, it may be that she now sees her uncle's welding in a different light, perhaps as having more connection to STEM: such knowledge/culture hybridity can move in both directions. In this moment, soldering in her own contextual manner, the girl demonstrated how her personal standpoint and the type of soldering knowledge she possessed shaped her 
embodied objectivity - in a way that highlighted the relational qualities of skill, community, family, and artistic interest.

\section{Generative context case 3: not-school}

Since the end of the 20th century, urban agriculture as a food production method has seen renewed interest. This investment represents, while only a fraction of the food production in the US, an important site for thinking about the potential for generative contexts that are possible with CRT education in places that are like school-they engage in rigorous learning around curriculum content-but are not-school (Sefton-Green, 2013). The renewed interest comes at a time when education reformers are looking for ways to engage underrepresented students and encourage them to pursue science careers (Lyles, 2016). This interest also creates the opportunity to see what kinds of social and material CRT arrangements are most fruitful for generative growth. By understanding the generative potential of projects where underrepresented students are engaged in rigorous CRT education out-of-school, we may be able to create a just, anti-hegemonic science. Whereas a hegemonic science would be ambivalent or silent on the question of power (Aronowitz, 1988), anti-hegemonic science does not just aim for more racially and ethnically diverse groups of scientists, but improves the socio-material conditions for those who are underrepresented and disenfranchised (Roth \& Barton, 2004).

Our case study occurred when a school serving African American youth in New York City collaborated with the Rensselaer Polytechnic Institute in the summer of 2015 to host a threeday workshop for students titled, "E-Waste to Makerspace." During the event, students were challenged to design an urban food system, using e-waste to make automated watering cans. The culturally responsive idea was that low-income folks might have multiple jobs and responsibilities that make it difficult to water their gardens. We put the students to the task of thinking about the way that urban food systems impacted low-income communities, the compound effect of environmental toxins on human health in urban areas, and the role that science could play in addressing these issues. The students, with researcher guidance, created a machine driven watering system for houseplants using parts from reclaimed computers. The machines were disassembled for parts, reassembled and wired with Arduinos. The students also created presentations reflecting their completed devices and how environmental toxins from electronic and industrial production affect social problems in urban centers. 
In the course of the project, students displayed many of the key elements that suggest a generative context. On pre-tests, these students indicated that the importance of science and technology was primarily in the biomedical and transportation areas. They viewed food production as entirely left to stores and large, shopping chains. Farmers, scientists, and urban environments were relatively absent in their pre-test descriptions of sources for food access. In post-tests following the workshop, students drew together the ideas of companion growing in urban agriculture and social solidarity to suggest that what is important about science is its capacity to help people solve their immediate food problems. Thus they framed solidarity as the foundation for doing good science. The researchers for this project took answers such as "Urban gardening will allow people in cities to get their food" and "Science can help people by giving them different options to garden. And also by solving some of the world's issues" as evidence that that understanding of solidarity had changed (Lyles, 2016, p.184).

In their presentations to adults and peers that accompanied the design project, students discussed how environmental toxins were both a danger to community solidarity and human life. In two presentations students focused on the direct risk of contamination of human water supplies with e-waste. In their presentations and post-tests, students made the connection between urban food systems and e-waste by noting that environmental toxins make food harder to produce for low-income communities and less nutritious when it is still possible. One group pointed out that while the US produces most of the e-waste burdening poor populations in the developing world, it does not have to suffer the consequences of the consumption of these electronic devices. The solution levied here is obvious: the US must take greater responsibility for the toxins it produces around the world and consider changing its consumption patterns of toxic materials.

These insights developed by the participants are important for directing our attention to what a generative context can tell us about the possibility of justice. Rather than separating out different domains (scientific, economic, agricultural, etc.) the students found common cause amongst different spheres of thought in order to further their interests and commitments. Their activity in equating companion growing with social solidarity reflects Haraway's (2015) insistence that we "make kin, not babies" in finding productive relationships and entanglements in the natural world with both humans and non-humans if we are to survive. For example, students connected the death of Freddie Gray, (a young AfricanAmerican whose unjust death at the hands of police set off the Boston protests against police brutality in 2015) to the lead poisoning that was found in his body during autopsy, and from 
there to the toxins of e-waste their "upcycling" was trying to address (Marbella, 2015). This shows how they are able to take insights in one domain and use science not just to frame his death but to deepen their understanding of how environmental systems connect to each other to produce layers of injustice (Lyles, 2016).

The generative context that these projects may produce is of critical importance for thinking about CRT education in not-school. Urban agriculture as CRT is provocative in that it is amenable to supporting deeper understanding and interest in science content without being a part of the traditional school paradigm. For some students, it is the disinterested and overly universal environment of normative science education that is inhibiting. Instead, these alternative sites provide an opportunity to develop the kinds of attention to the material world, development of social decision-making capacity, and symbiosis between material and social conditions that deep CRT requires. CRT combined with urban agriculture is not necessarily a generative context, and each engagement will need to take advantage of the specific conditions at hand. But, the successes in this domain will help point to a broader conception of the underlying principles of diversity that is necessary to the larger understanding of generative justice.

\section{From context to justice}

In the three case studies above, a generative context was cultivated for the purposes of building culturally relevant assets-braiding, soldering, and gardening technologies-by making them part of students' educational experiences in-school, after-school, and not-school. These generative contexts are based within our generative justice framework for CRT that has emerged from building on relevant community knowledge. These generative context instantiations gave students a wide degree of latitude to inquire about the links between sociomaterial conditions and STEM practice and knowledge. Further, it encouraged students to conceptualize how STEM knowledge and practice could be operationalized in service of social justice.

In common, each case aimed to generate the conditions for unalienating forms of CRT by grounding it in students' community experiences and cultural heritage. Yet, they differed in their requirements for generating contexts where value can circulate between educational and community settings. In the structure of in-school, the generative context for building cornrow braiding as a cultural and educational asset tightly coupled the hairstylist's classroom intervention with teachers' goals. The teacher wanted to build on her goals to teach students 
programming and Angela's braiding expertise aided that goal. However, there was no clear way in which this collaboration could benefit Angela's own practice and salon. In the openended after-school program, a student's freedom to creatively construct and deconstruct electronics opened a pathway for her to demonstrate advanced soldering skills to teachers and peers. Because soldering is a fundamental skill for many in the Maker Movement, this student's family knowledge was brought to bear on an educational setting where it would otherwise go overlooked. While the program was good at incorporating students' knowledge into after-school, it provided little direction for fostering that skill in a larger community and peer setting, such as at a Maker Faire or with a fixing group. A blending of traditional inschool curriculum and open-ended "learning by doing" was required for a generative context to be cultivated in the not-school "E-Waste to Makerspace" workshop. Students used a mix of community, technical, and scientific knowledge to design an artifact - the automated watering can-that supported food justice goals. Yet, it was not connected to a specific community who may benefit but instead was isolated to the summer workshop. What would have been required to actualize these educational contexts as generative justice?

Many ways to answer this question exist because there is no single set of internal relations universal to generative growth. Instead many moving and interrelated parts create the required circulations of value. Figure 5 is a visual representation of flows of unalienated value that brings each of our case studies above into a complex relationship. Each case highlights one of the individual nodes discussed in a section, with language to describe the generative achievement that connects academic knowledge to community settings through CRT: building community assets in school; creating spaces for situated knowledge; developing social theory and practice to inform engagement with the natural world. Each case presented above is a particular example of the pre-conditions for a generative system. An ideal system for generative justice would include all three preconditions, directing the unalienated labor value, ecological value, and expressive value so that activities are mutually reinforcing. The potential for generative justice is not the conclusion of a set of actions, but the emergent ecosystem of asset building, situated knowledges, and socio-material engagement. Generative justice is the basin of attraction at the center of these unalienated activities. Through each example, we can see how the repeated and mutual flows of unalienated labor moving between generative contexts increases the possibility for generative justice to emerge. 


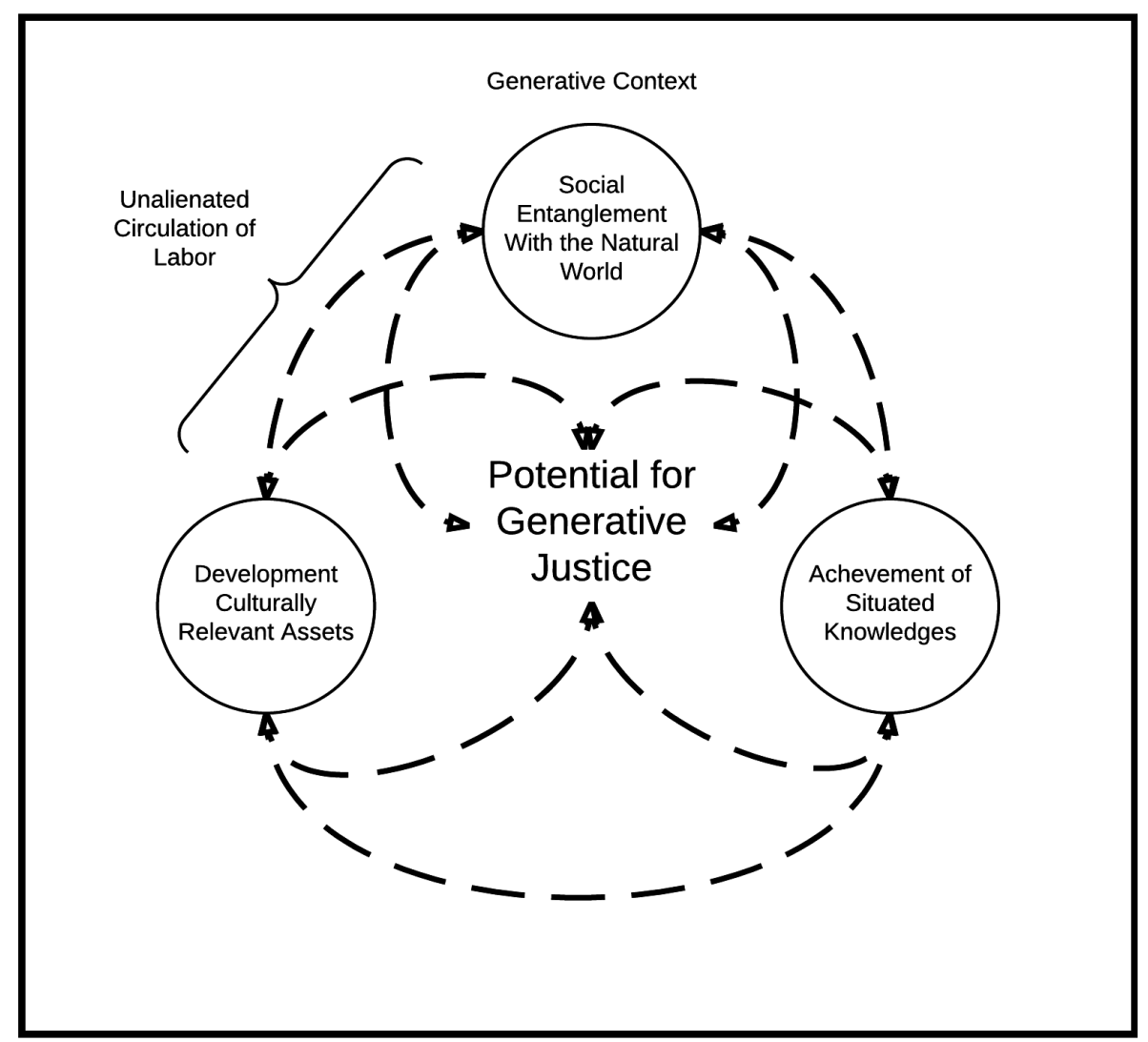

Source: Own production.

To move from generative context to generative justice requires tracing out and following the connections and relationships that contribute to that specific context. The fact that we are speculating points to the importance of time for the development and observation of generative justice. Interrelationships and interconnecting parts must be cultivated, not in a single workshop or in-school activity but through ongoing attention and care. Where this attention and care comes from and how it is socially and financially supported will need to be determined by the culturally situated context. Financial support might be the biggest barrier to the incorporation of a generative context within education, as it often focuses on local, marginalized, and economically disadvantaged communities. At the same time, social support 
is often limited due to broad government cuts in social welfare and teachers' lack of control over their classrooms.

What is clear at this point is that both capitalist accumulation and centralized state control will fail to bring about top-down forms of justice. Generative justice offers a compelling, bottom-up alternative. By describing cases of CRT that are implemented using a generative justice framework, we have sought to begin a discussion for how educators might create contexts for generative growth to the benefit of both schools and communities-hopefully beyond financial means. Since all the cases above stopped at education, it is hard to say if there were any that moved from context to justice; however, there is reason to be hopeful.

After the Cornrow Curves workshop, a member of our research team visited Angela to deliver some student-designs for her to display on the walls of her salon. During the visit Angela explained that a customer had heard about the work, allowing them to discuss Cornrow Curves during an appointment. While only one instance, this exchange demonstrates the power that generative contexts have for circulating value between schools and communities. Not only was the cultural practice of cornrow braiding brought to bear on computing in school, but also computing was brought to bear on braiding in the hair salon. Through a generative justice framework, CRT is best realized when it provides a generative context where value between the school and community are mutually reinforcing, as the example in Angela's salon alludes to. We can speculate on other examples, such as students who are excellent at braiding taking computer-programming courses. Or, perhaps we should follow up on the students who were in the "E-Waste to Makerspace" workshop to see if they started an e-waste recycling program. Long-term experimental work at the intersection of educational practice and research is required to move beyond speculation.

\section{Conclusion}

To dismantle testocracy and develop the theory of generative justice, this paper has introduced the concept of generative context to describe the socio-material conditions where generative justice is possible. The three educational generative contexts above aim to use CRT to restore students' agency in-school, after-school, and not-school. Through community connections, we explored generative context as a possibility for resisting alienation in educational settings by using CRT to cultivate knowledge acquisition while recognizing and giving weight to the specific knowledges and experiences that students already possessed. The 
expectation is that the learning experience does not end at the site of education, since knowledge starts with and is iteratively brought back into the community. This epistemological looping can help to build community assets by making them innovations in education. Instead of alienating top-down systems for the dissemination of knowledge for all, this model is generative and sustaining. It demonstrates that by setting up a fertile and robust context, educational practices can highlight, build, and blossom in conjunction with deeprooted community relationships, knowledges, and needs. 


\section{References}

Anyon, J. (2014). Radical Possibilities: Public Policy, Urban Education, and a New Social Movement. New York: Routledge.

Aronowitz, S. (1988). Science as Power: Discourse and Ideology in Modern Society. Minneapolis: University of Minnesota Press.

Bennett, A., Eglash, R., Lachney, M., and Babbitt, B. (2016). "Design Agency: Diversifying Computer Science at the Intersection of Creativity and Culture.” In M. Raisinghani (Ed), Revolutionizing Education through Web-Based Instruction (pp. 35-56). London: IGI Global.

Brown-Jeffy, S., \& Cooper, J. E. (2011). Toward a Conceptual Framework of Culturally Relevant Pedagogy: An Overview of the Conceptual and Theoretical Literature. Teacher Education Quarterly, 38(1), 65-84.

Chappell, B. (2001). "Take a Little Trip with Me" Low Riding and the Poetics of Scale. In A. Nelson, T. L. N. Tu, (Eds) with A. Headlam Hines (Contributor), Technicolor: Race, Technology, and everyday life (pp. 100-120). New York: New York University Press.

Dougherty, D. (2012). Darpa Mentor Award to Bring Making to Education. Make Magazine. Retrieved from <http://makezine.com/2012/01/19/darpa-mentor-award-to-bring-making-to-education/>.

Drew, D. E. (2011). STEM the Tide: Reforming Science, Technology, Engineering, and Math Education in America. Baltimore: Johns Hopkins University Press.

Dewey, J. (1915). The School and Society. Chicago: The University of Chicago Press.

Eglash, R. (1997). When Math Worlds Collide: Intention and Invention in Ethnomathematics. Science, Technology \& Human Values, 22(1), 79-97.

Eglash, R. (1999). African Fractals: Modern Computing and Indigenous Design. New Brunswick: Rutgers University Press.

Eglash, R., Bennett, A., O'donnell, C., Jennings, S. \& Cintorino, M. (2006). Culturally Situated Design Tools: Ethnocomputing from Field Site to Classroom. American Anthropologist, 108(2), 347-362.

Eglash, R. (2016). Of Marx and Makers: An Historical Perspective on Generative Justice. Teknokultura, 13(1), 245-269. 
FreIRE, P. (1970). Pedagogy of The Oppressed. New York: Herder and Herder.

GAY, G. (2010). Culturally responsive teaching: Theory, research, and practice. Teachers College.

Haraway, D. (1991). Simians, Cyborgs, and Women: The Reinvention of Nature. New York: Routledge.

Haraway, D. (2015). Anthropocene, Capitalocene, Plantationocene, Chthulucene: Making Kin. Environmental Humanities, 6(1), 159-165.

Haring, K. (2008). Ham radio's technical culture. Cloth

LaChNeY, M. (2016). Culturally responsive computing as brokerage: toward asset building with education-based social movements. Learning, Media and Technology, 1-20. DOI: $10.1080 / 17439884.2016 .1211679$

Lachney, M., Bennett, A., Appiah, J. \& Eglash, R. (2016). Modeling in Ethnocomputing: Replacing Bi-Directional Flows with Recursive Emergency. International Journal for Research in Mathematics Education, 6(1), 219-243.

Lachney, M., Babitt, W. \& Eglash, R. (2016). Software Design in the 'Construction Genre' of Learning Technology: Content Aware Versus Content Agonistic." Computational Culture: A Journal of Software Studies 5. Retrieved from

$<\mathrm{http}$ ://computationalculture.net/article/software-design-in-the-construction-genre-oflearningTechnology-content-aware-versus-content-agnostic>.

Ladson-Billings, G. (1995). Toward a Theory of Culturally Relevant Pedagogy. American Educational Research Journal, 32(3), 465-491.

Lipka, J., Монатт, G. V., and The Ciulistet Group. (1998). Transforming the Culture of Schools: Yup’ik Eskimo Examples. Mahwah: Lawrence Erlbaum Associates.

Lipman, P. (2011). The New Political Economy of Urban Education: Neoliberalism, Race, and the Right to the City. New York: Routledge.

Lyes, D. (2016) Generative Contexts. Doctoral dissertation, Rensselaer Polytechnic Institute.

Kонит, L. M. (2014). The Impact of Teacher Expectations on Student Achievement (Doctoral dissertation, Indiana University of Pennsylvania.

Maker Education Initiative. (2015). Youth Makerspace Playbook. Retrieved from $<$ http://makered.org/wp-content/uploads/2015/09/Youth-Makerspace-Playbook_FINAL.pdf>. 
Marbella, J. (2015, April 23th). Beginning of Freddie Gray's life as sad as its end, court case shows. The Baltimore Sun. Retrieved from

$<$ http://www.baltimoresun.com/news/maryland/baltimore-city/bs-md-freddie-gray-lead-paint20150423-story.html\#page=1>

Maxigas, M. (2014). Hacklabs and Hackerspaces - Tracing Two Genealogies. Journal of Peer Production, 1 (2). Retrieved from

$<$ http://peerproduction.net/issues/issue-2/peer-reviewed-papers/hacklabs-and-hackerspaces/>

Morozov, E. (2014). Making it. New York Times. Retrieved from

$<$ http://www.newyorker.com/arts/critics/atlarge/2014/01/13/140113crat_atlarg emorzov? currentPage $=$ all $>$

PAPERT, S. (1993). The Children's Machine: Rethinking School in the Age of the Computer. New York: Basic Books.

Rich, M., Cox, A., \& Bloch, M. (2016, April 29) Money, Race and Success: How Your School District Compares. The New York Times. Retrieved from

$<$ http://www.nytimes.com/interactive/2016/04/29/upshot/money-race-and-success-how-yourschool-district-compares.html?_r=0>

Nguyen, T. (2008). Information, Role Models and Perceived Returns to Education: Experimental Evidence from Madagascar. Unpublished manuscript, 6.

Hagopian, J. (2014). Preface: The Testocracy versus the Educational Spring. In J. Hagopian (Ed) More than a Score: the New Uprising Against High-Stakes Testing (pp. 7-27). Chicago: Haymarket Books.

Richard, G. T. \& KafaI, Y. B. (2016). Blind spots in youth DIY programming: Examining diversity in creators, content, and comments within the scratch online community. In Proceedings of the 2016 CHI Conference on Human Factors in Computing Systems (pp. 1473-1485). ACM.

Roth, W. M., \& Barton, A. C. (2004). Rethinking Scientific Literacy. New York: Routledge.

Scott, K. A., Sheridan, K. M. \& Clark, K. (2015). Culturally Responsive Computing: A Theory Revisited. Learning, Media and Technology, 40(4), 412-47-98.

Sefton-Green, J. (2012). Learning at Not-School: A Review of Study, Theory, and Advocacy for Education in Non-Formal Settings. Cambridge, MA: MIT Press.

Spencer, A. (2005). DIY: The Rise of Lo-Fi Culture. New York, NY: Marion Boyars. 
Toupin, S. (2014) Feminist Hackerspaces as Safer Spaces? Feminist Journal of Art and Digital Culture. Retrieved from http://dpi.studioxx.org/en/feminist-hackerspaces safer-s36.

Zernike, K. (2015) Obama administration calls for limits on testing in school. New York Times. Retrieved from

<http://www.nytimes.com/2015/10/25/us/obama-administration-calls-for-limits-on-testing-inschools.html>. 